Portland State University

PDXScholar

$5-24-2019$

\title{
Sustaining Rural Place: Rethinking Design Principles for Social Sustainability in Rural America
}

Carlie C. Donnelly

Portland State University

Follow this and additional works at: https://pdxscholar.library.pdx.edu/honorstheses

Let us know how access to this document benefits you.

\section{Recommended Citation}

Donnelly, Carlie C., "Sustaining Rural Place: Rethinking Design Principles for Social Sustainability in Rural America" (2019). University Honors Theses. Paper 722.

https://doi.org/10.15760/honors.739

This Thesis is brought to you for free and open access. It has been accepted for inclusion in University Honors Theses by an authorized administrator of PDXScholar. Please contact us if we can make this document more accessible: pdxscholar@pdx.edu. 


\title{
Sustaining Rural Place: \\ Rethinking Design Principles for Social Sustainability in Rural America
}

\author{
Written by \\ Carlie Donnelly \\ An undergraduate honors thesis submitted in partial fulfillment \\ of the requirement for the degree of \\ Bachelor of Science in \\ University Honors, \\ Architecture, \\ and Arts and Letters
}

Thesis Adviser

Sergio Palleroni

Portland State University

2019 
Abstract

Key Words: placemaking, urban design, rural development, place-based theory

Although the population of Rural America is declining, we will likely never live in a country that does not need rural communities to sustain our natural resources. The field of urban design has developed great strategies for creating livable communities, but they are not universal strategies. The design of rural towns and community places has been neglected from the conversation of urban design principles as they are not directly applicable because of Rural America's lack of density which also results in an alternate social system. Through analysis of urban design principles and rural place making case studies, this thesis bridges the gap and finds that maximizing systems and prioritizing efficiency are the common elements of successful place making. In an effort to make these findings tangible to rural community leaders and design professionals working in rural communities, the conclusion presents a booklet describing Four Focuses of Attention to Sustain Rural Place. The four focuses are representation, agency, access, and centralization which should be given priority when applying design principles to communities of Rural America upon new construction, renovation, or revitalization. 
Table of Contents

1 Introduction

2 Analysis of Social Systems

3 Designing for Livability

4 Case Studies: Rural Public Spaces

5 Four Focuses of Attention

5.1 Representation

5.2 Agency

5.3 Access

5.4 Centralization

6 Conclusion: Making Urban Design Prevalent + Creating A Tangible Tool

Bibliography

Appendices

A: The AIA's 10 Principles for Livable Communities

B: Analysis of 10 Design Principles for Livable Rural Communities, Design: SD

C: A Guide to Sustaining Rural Place: A Tool For Rural Leaders 


\section{Introduction}

As the population of the United States increases, the population is also migrating. Americans are abandoning the rural counties of the country because of the loss of jobs in farming and manufacturing-dependent counties. Annually, the United States Department of Agriculture Economic Research Service takes count of the population in each county in the United States and compiles the data to track migration within the country. Figures 1, 2, and 3 clearly illustrate the shift towards metropolitan areas and an increase in counties experiencing population decline. The 2008 recession is in part responsible for a greater presence in metropolitan areas; the dwindling population of Rural America due to a decrease in rural manufacturing jobs increased with the recession as well as global competition and technological changes. The decreasing population rate of farming dependent counties slightly improved between 2001 and 2008, but this was more due to an increase in energy-related jobs. Still, farming and manufacturing dependent counties are in decline because of their aging population. ${ }^{1}$

Fewer people means less attention and fewer resources as focus remains on greater populated areas under the assumption that this is looking at the country as a whole. It would be easy to assume that America is eventually going to solely populated in Metropolitan areas; however, there will not be an America without rural counties as they are the holder of many natural resources and potential energy collection. These community's economic role in America will continue to demand a population to work in the area. Though fewer people means less daily resources, the communities formed at the heart of the country require the attention and resources equal to those of Metropolitan America. The life of communities and families in Rural America will remain essential to the social and economic wellbeing of our Metropolitan areas.

\footnotetext{
1 "Shifting Geography Of Population Change". 2018. USDA ERS. https://www.ers.usda.gov/topics/rural-economy-population/population-migration/shifting-geogra phy-of-population-change/.
} 


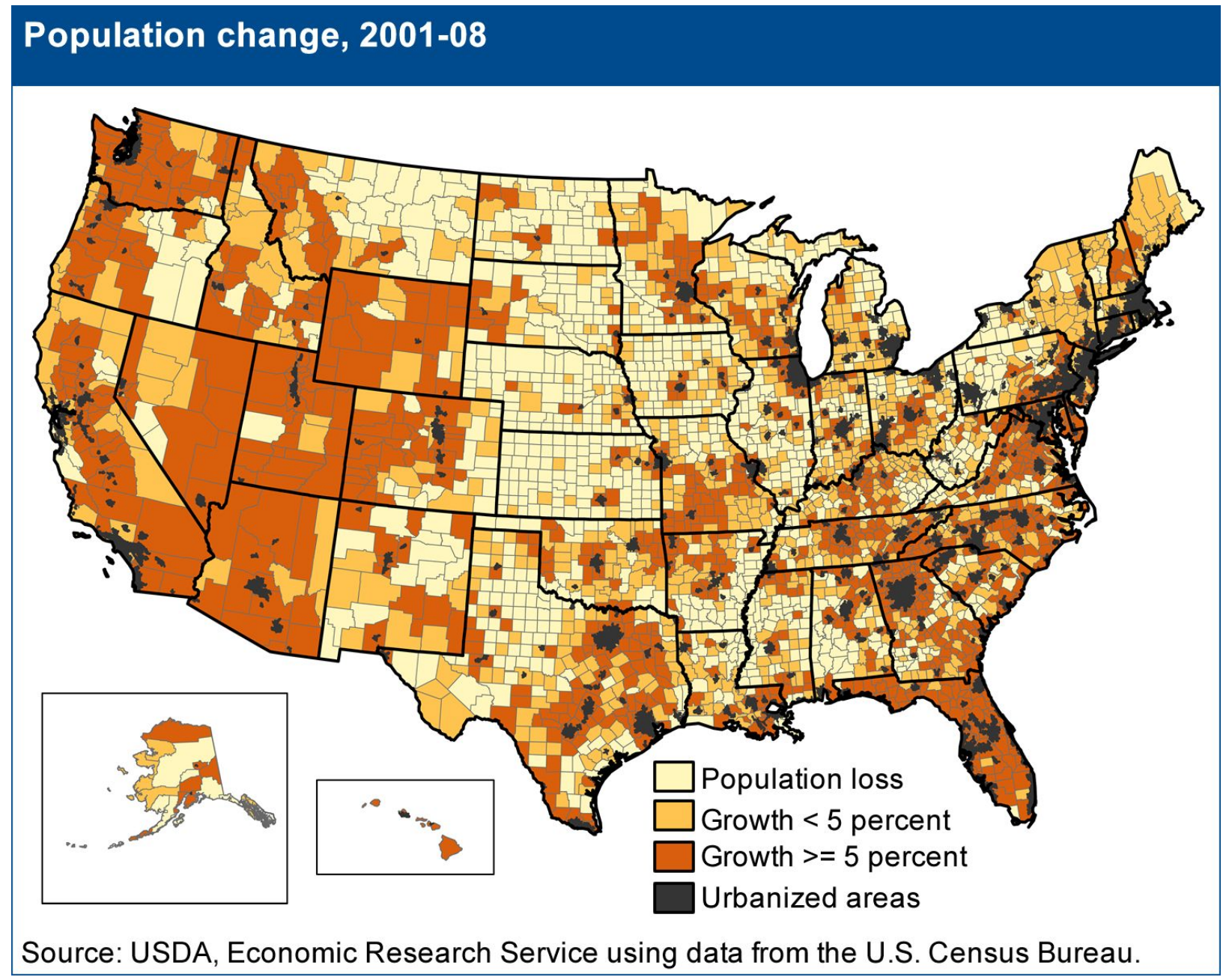

\section{Figure 1}

A display of counties experiencing population loss between 2001 and 2008. With Figure 2, displaying an increase in American counties that are experiencing population loss. 


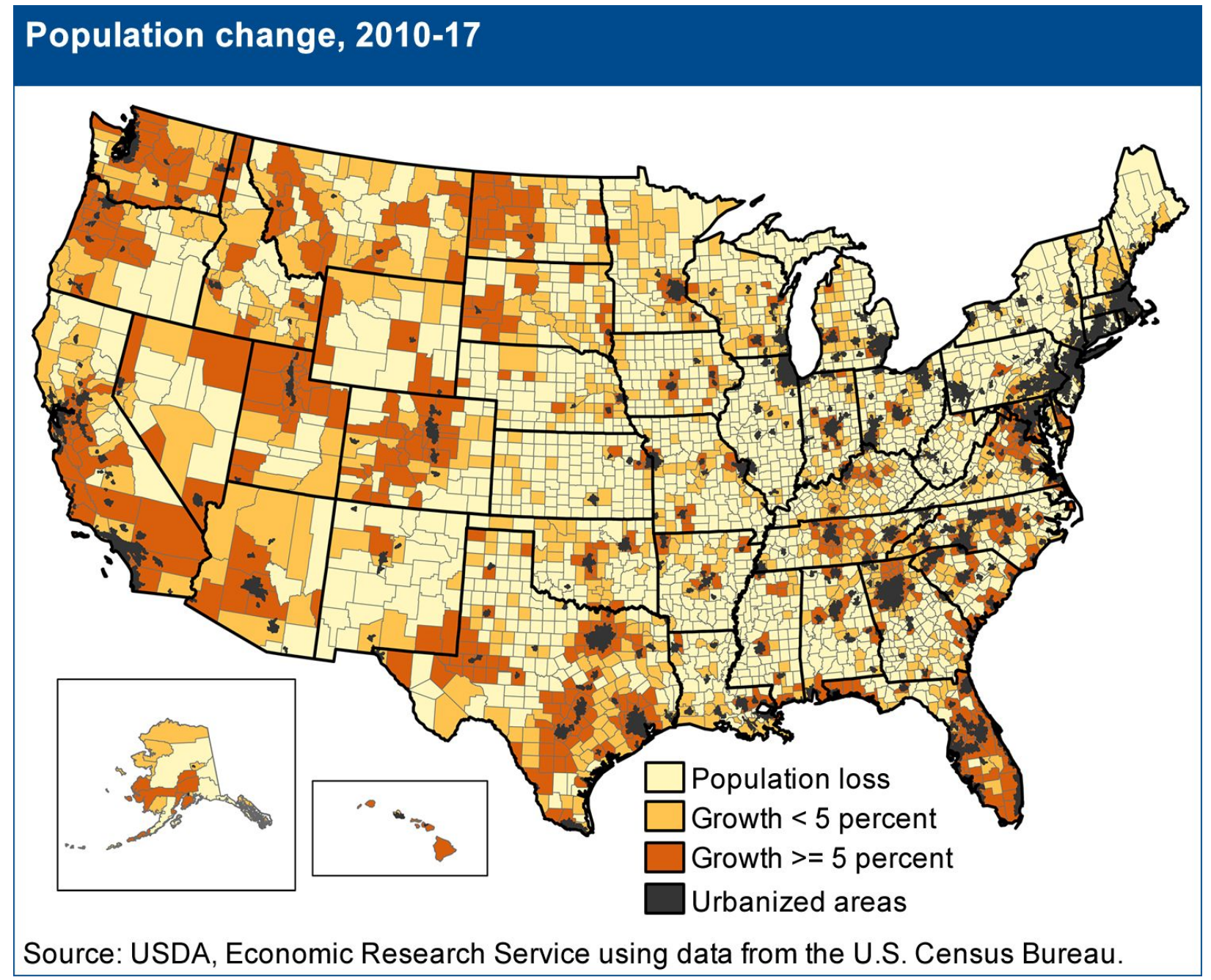

\section{Figure 2}

A display of counties experiencing population loss between 2009 and 2010. With Figure 1, displaying an increase in American counties that are experiencing population loss. 


\section{Population change by county's place on the rural-urban continuum,}

2001-08 and 2010-17

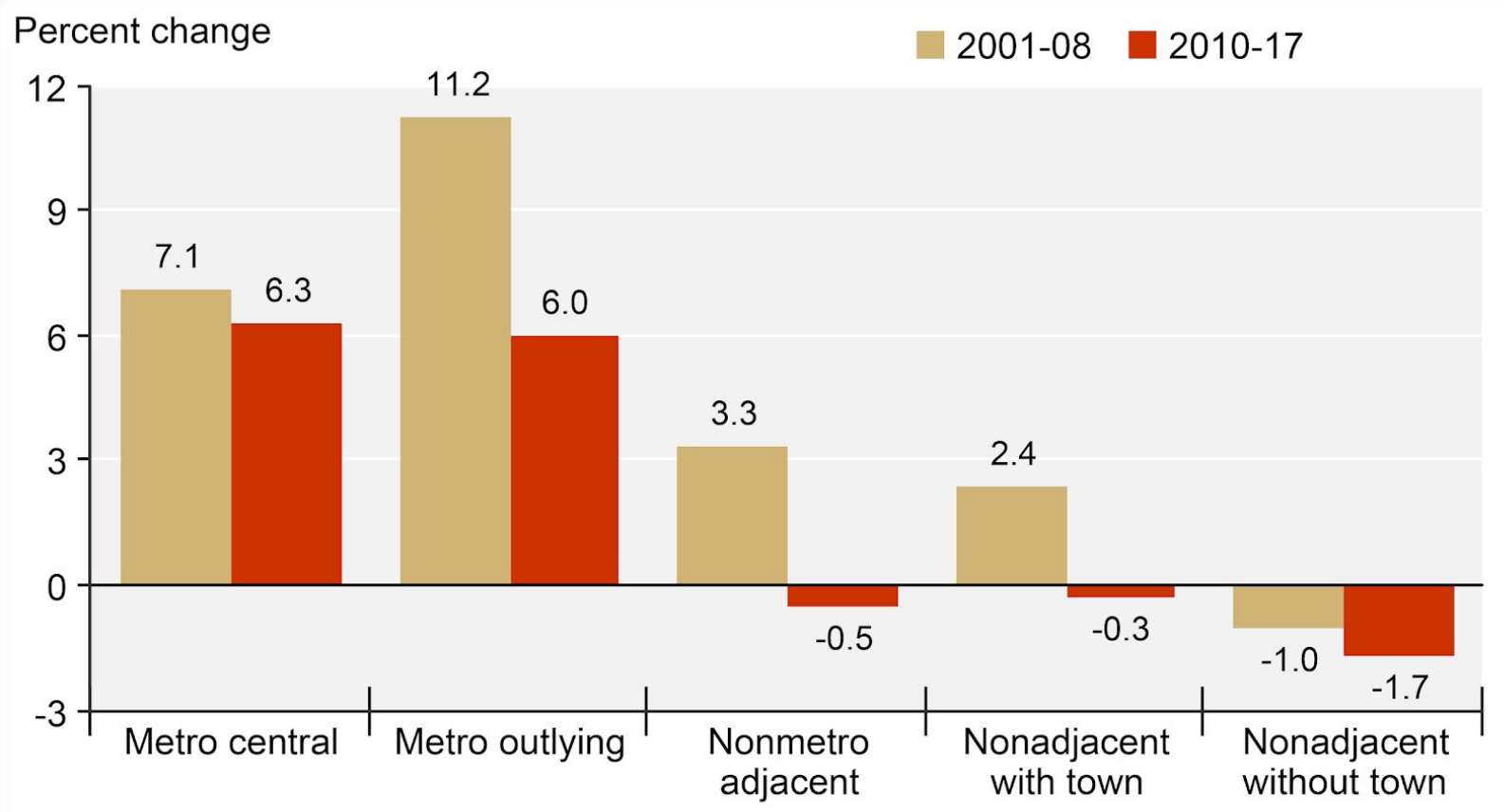

Note: Categories are based on 2013 metro definitions. Metro central counties contain urbanized areas of 50,000 people or more. Metro outlying counties are tied to central counties through high commuting levels ( $25 \%$ and higher). Nonmetro adjacent counties are both physically adjacent to a metro area and have 2-25 percent commuting to the central counties. Nonadjacent counties are divided into those with and without urban populations. Source: USDA, Economic Research Service using data from the U.S. Census Bureau.

Figure 3

Displaying the significance of the economic recession on decreasing populations in nonmentro areas. 
There has been a lack of attention to fostering the design of rural communities which is leaving Americans with equally complex lives to be left out of what seem like should be simple implementations and benefits that are seen in Metropolitan America. This is because when generic applications have been attempted, they do not quite work the same or sustain in a town of a few hundred as they do for a city of thousands. There is a requirement to take what the design industry has learned from Metropolitan America and make it intentionally applicable to Rural America.

The principles of placemaking as defined by contemporary urban design do belong in the conversation of protecting, preserving, and sustaining Rural America, but they must be redefined for a different social system, occupancy, and usage from Metropolitan America for flourishing economic and social sustainability. The practice of urban design has made wonderful progress and adopted significant principles which benefit greatly to areas of dense population, but these principles are innately biased towards areas of dense population. In 2005, the American Institute of Architects (AIA) established the AIA's 10 Principles for Livable Communities in their publication Livability $101 .{ }^{2}$ This publication assumes an urban environment and the principles defined and widely accepted are assuming of an urban environment. These principles have been formed to help Metropolitan America which has a different population situation than Rural America; the population density found in Metropolitan America is what is making these principles work. Community leaders and designers must recognize this difference and realize that direct application of principles that work in Metropolitan America will not work the same when applied in Rural America.

The urban environment is distinguished from the rural environment by its population density as well as a difference in social structure and meanings of security. Population density is an interesting statistic in designing and planning at a large scale because it is both precisely measurable and has an intangible effect on the types of spaces that will be designed for a certain place because of its density characteristic. The intangible effect must first be understood at both an urban design, and architectural scale as an effect that has only previously been assumed as a physical density difference in practice.

\section{Analysis of Social Systems}

The economic and cultural contexts of Rural America are rarely defined by their state and county lines and are more consistently divided by their climatic and economic typology. Robert

\footnotetext{
${ }^{2}$ The American Institute of Architects. 2005. "Livability 101: What Makes A Community Livable?". Washington D.C.: The American Institute of Architects. https://www.aia-mn.org/wp-content/uploads/Livability101.pdf.
} 
Thayer's Life Place ${ }^{3}$ discusses and connects the condition of a bioregion to the economy. Life Place has been developed as a methodology and belief from observing farming-dependent communities and is in the context of approaching place's relationship to the economic strata of our society.Through this connection, Thayer has developed a premise on realizing that the meaning of place and the methods that 'awaken' a place rely on the natural state and the unique attributes of a specific place. Thayer also establishes that understanding where a person is located is an essential key to human understanding and purpose; therefore giving great value to the physical location of someone at any moment. Thayer also makes the startling comment that although humans are concentrating more than ever, humanity is losing a sense of wholeness in our existence. Humans have compartmentalized their livelihoods and are the most individually isolated and alienated than ever before.

As we look at the current planning and design of Rural America, Forbes Lipschitz brings us to realize that there has been a lack of difference is design typology across Rural America, a neglect of any consideration to "life place". Rural America is often home to essential systems and institutions such as prisons, livestock farms, and landfills, but across they board, they all look the same (Figure 4) - which is quite rough. They lack any aspect which might enhance one's experience let alone gain any strategic benefit. If these essential systems are being shoved aside for the urban interest that currently bombards contemporary architecture, there's no way that the people who encounter these institutions, especially those who work there, are receiving the benefits of enhancement in design. The urban fabric of Rural America currently assumes that the landscape and people are homogenous when in fact rural towns should be looked at more like neighborhoods are in metropolitan america in that they are unique in their needs and way of life.

${ }^{3}$ Thayer, Robert L. LifePlace: Bioregional Thought and Practice. Univ of California Press, 2003. 

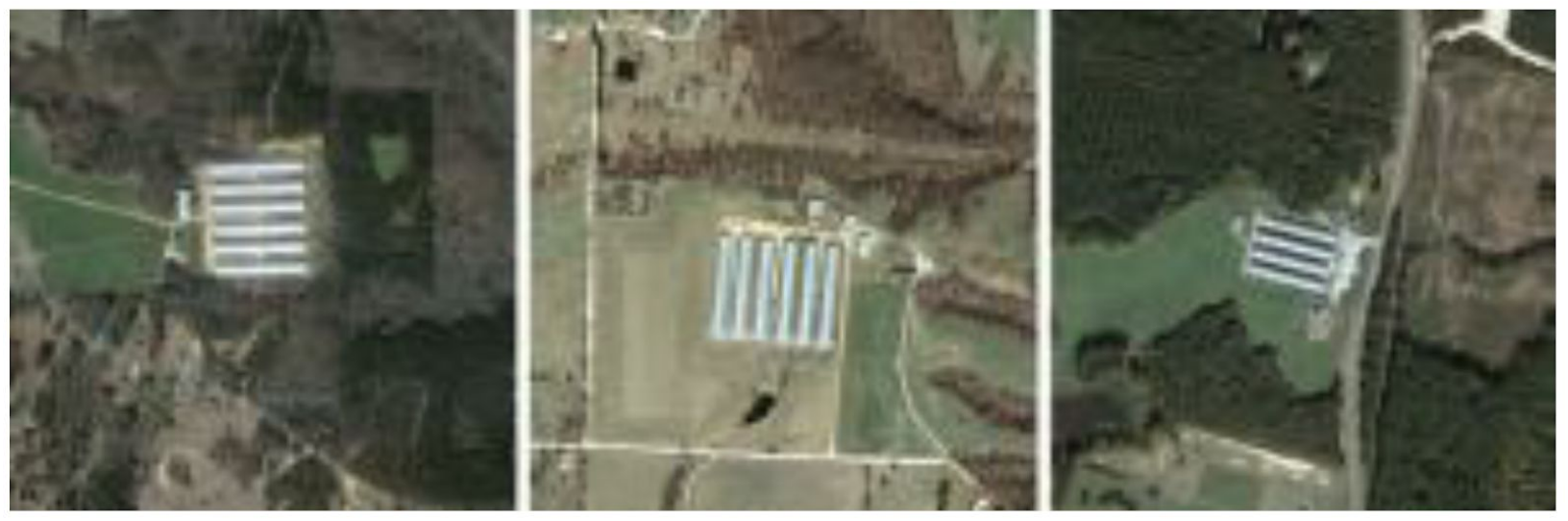

Figure 4

From Forbes Lipschitz: "Aerial photographs of CAFOs demonstrate lack of geographic specificity. From left to right: poultry farms in Alabama, Arkansas and Virginia"

The work of Jessica Ulrich-Schad of South Dakota State University and Cynthia Duncan of Carsey School of Public Policy in the Journal of Peasant Studies is summarized by Richard Florida in his article The 3 Rural Americas for City Lab. ${ }^{4}$ The work done by Ulrich-Schad and Duncan defines three types of Rural America: chronically poor, transitioning, and amenity-rich. Florida's summary describes the characteristics of Rural America towns that are thriving versus those that are dwindling. Towns and communities identified as chronically poor are the ones in decline; these are areas affected by inter-generational economic hardship, low levels of educational attainment, job loss, and unemployment. Young people are getting out of these areas and the remaining are aging out the population. Transitioning rural areas (which are of the type that this thesis aims to assist) are shifting in both demographics and economies. These places were once hurting because of deindustrialization and have centered their economies on resource-based industries like agriculture and manufacturing. Their populations are increasing, but the population of young adults between the ages of 25 and 34 is taking a hit of eighteen percent. Amenity-rich rural areas (also the type that this thesis aims to assist) exists within recreational and aesthetically intense natural amenities. The aesthetics of these communities has attracted new residence and has been able to build more stable economies because of it. Although the median household income is below the national average in these communities, the population of adults between the ages of 25 and 34 has increased and their economies are considered more stable.

${ }^{4}$ Florida, Richard. 2018. "The 3 Rural Americas". Citylab. https:/www.citylab.com/equity/2018/06/the-three-rural-americas/561791/. 
The work of Gintaras Stauskis and Frank Eckardt ${ }^{5}$ acknowledges the relationship between designed and planned places and their socioeconomic effect on the community. Their research focuses on urban spaces in Germany; however, the identified relationships of structural and esthetic transformations to socioeconomic relations in these urban environments are applicable globally.

We need to recognize that implementing change (whether that be tangible built change or policy) to connect urban design to place making interventions in the rural context will not take the same trajectory in a different social system. Smaller scale interventions of urban design on social growth happen at an architectural scale of place making in the rural context rather than at a large planning scale that is seen in cities. Works of urban design must approach projects in Rural America with a different social understanding of sustaining community in mind. Urban design bases its findings and methods on a certain population density. This density is what shapes the actions towards social sustainability which has governed the studies of urban design, but we do not have the benefits of density innately available in Rural America.

The distinguishing difference between Rural America from Metropolitan America (density) results in a different social system that is seen from the public sphere to the personal sphere. Actually, these spheres are much more interconnected in Rural America than in Metropolitan America, and this greatly affects the functioning of the urban fabric in Rural America. These factors are essential to understanding the difference between designing and planning for the types of communities that exist within these. Think about walking down the sidewalk in the city in comparison to walking down the sidewalk in a rural town. This starts to explain how walking in the city brings about animosity and the concept of being lost in the crowd. One can be invisible. Whereas, if you cross paths with someone on a rural street, you are sure to acknowledge one another. This just begins to describe the difference in the social structure of Rural America in contrast to Metropolitan America. Now we must ask, what approaches can be taken to support the social sustainability of Rural America? How can community leaders make sure they are implementing strategies that support rural place?

\section{Designing for Livability}

Designing for livability in the rural environment requires designers to be in a mindset of a smaller scale and to think of results for a smaller population. Design:SD (South Dakota) and the SEED Network have created metrics which community leaders can put in place to make design

\footnotetext{
${ }^{5}$ Stauskis, Gintaras, and Frank Eckardt. "Empowering Public Spaces as Catalysers of Social Interactions in Urban Communities." Town Planning and Architecture 35, no. 2 (2011): $117-28$.
} 
decisions about what will benefit the rural town or community socially as well as economically. The American Institute of Architects 10 Principles for Livable Communities ${ }^{6}$, published in 2005, summarizes urban design concepts that lead to well fostered communities; they identify the priorities which the architect must take in order to implement social change in communities. Though, the preference of community types that these 10 Principles accommodate to is that of Metropolitan America. These principles rely on assumed density and consistent additions to make them function as intended.

In 2007, Design: SD was established and serves Rural America by visiting one community per year with a three-day design charrette. The organization which is in partnership with AIA South Dakota, Dakota Resources, and South Dakota State University, published an adaptation to AIA's 10 principles attempting to set go to standards for Rural America ${ }^{7}$. Their publication is titled 10 Design Principles for Livable Rural Communities. Design South Dakota acknowledges the sparse population of Rural America by adjusting the majority of AIA's initial proposals. The adaptation removes verbiage from the original 10 principles that do not apply to rural communities such as urban centers and neighborhoods and replaced them with smaller-scale terms including community and residents. Figure 5 below shows the adapted statements. For the adapted descriptions, please reference Appendix B.

\footnotetext{
${ }^{6}$ The American Institute of Architects. 2005. "Livability 101: What Makes A Community Livable?". Washington D.C.: The American Institute of Architects. https:/www.aia-mn.org/wp-content/uploads/Livability101.pdf.

${ }^{7}$ Design: SD. 2007. "10 Design Principles For Livable Rural Communities". Brown County, South Dakota: Dakotafire Media. http://www.designsd.org/design-principles.html.
} 


\section{The AIA's 10 Principles for Livable Communities}

Design on a Human Scale

Provide Choices

Encourage Mixed-Use Development

Preserve Urban Centers

Vary Transportation Options

Build Vibrant Public Spaces

Create a Neighborhood Identity

Protect Environmental Resources

Conserve Landscapes

Design Matters
10 Design Principles for Livable Rural Communities

$\rightarrow \quad$ Design on a human scale.

$\rightarrow \quad$ Provide choices.

$\rightarrow \quad$ Plan for mixed uses.

$\rightarrow \quad$ Preserve the community's core.

$\rightarrow \quad$ Build connections.

$\rightarrow \quad$ Create shared social and public spaces.

$\rightarrow \quad$ Promote community identity.

$\rightarrow \quad$ Conserve natural resources and landscapes.

$\rightarrow \quad$ Develop strategies for economic development and marketing.

$\rightarrow \quad$ Design matters.

Figure 5

An initial comparison between AIA's original 10 principles and Design: SD's adaptation

Another organization working to implement sustainable systems into the design framework is the SEED Network. They are an organization for those in the design industry who operate on the same mission "to advance the right of every person to live in a socially, economically, and environmentally healthy community."8 Their methodology has been summarized in the following hey have developed 5 Principles:

\footnotetext{
8 "About - SEED Network". 2019. SEED Network. Accessed May 25. https://seednetwork.org/about/mission/.
} 
Five SEED Principles ${ }^{9}$

1. Advocate with those who have a limited voice in public life

2. Build structures for inclusion that engage stakeholders and allow communities to make decisions

3. Promote social equality through discourse that reflects a range of values and social identities

4. Generate ideas that grow from place and build local capacity

5. Design to help conserve resources and minimize waste

These principles inform an evaluation process which looks to make the design process participatory with the community who is to be impacted. This method is based on the success of projects which have included the community in design decisions. This inclusion allows the decision makers to understand the community's specific needs rather than making inefficient assumptions. The SEED Network offers the SEED Evaluator as its guide to implementing a truly sustainable product. These metrics of successfully designing livable places bridge the gap between quality of life, social sustainability, and economic sustainability and offer a method of decision making for Rural America to remain a vibrant heartland of the country.

\section{Case Studies: Rural Public Spaces}

The following organizations have specialized themselves in implementing design outside of the scope of Metropolitan America. University of Arkansas Community Design Center (UACDC) has become a leader in a systems based approach to community design. Rural Urban Framework has identified the essentialness of the "village" globally and encouraged the sustainability of these villages.

In Farmington Arkansas, The University of Arkansas Community Design Center (UACDC) has been given the challenge of a drive-through town. It's economy and vibrancy comes is sourced by the highway that runs through the center of town. Studying this case study is critical to understanding the automobile-oriented context that Rural America relies on to remain physically connected to the rest of the country. To create a walkable neighborhood, UACDC employed three strategies: a context-sensitive highway, public art planning, and agricultural

urbanism. ${ }^{10}$ "Unlike the totalizing pattern of a master plan, townscaping employs a serial

9 "Methodology - SEED Network". 2019. SEED Network. Accessed May 25. https://seednetwork.org/tools/methodology/.

${ }^{10}$ University of Arkansas Community Design Center. 2010. "Townscaping An Automobile-Oriented Fabric: Farmington, Arkansas". Fayetteville, Arkansas: UACDC. https://s3.amazonaws.com/uacde/Farmington_Townscaping-an-Automobile-Oriented-Fabric.pdf. 
organization of nodes to create a walkable urban environment within an automobile-oriented fabric. As a retrofit planning strategy, townscaping offers a model for an incremental urbanization without reliance on capital intensive architectural investments. The goal is to create a memorable town fabric for anchoring new growth in an otherwise fragmented and anonymous landscape."11

The implementation is Farmington centralize all traffic (automobile and pedestrian). Through strategic means, automobiles and pedestrians can be introduced to each other safely. The project in Farmington also exemplifies the combination of several ecosystems - arguably a man made ecosystem with the natural one by creating nodes of agriculture and lining the streets with fruit bearing plants. ${ }^{12}$

Through Village Urbanization, Rural Urban Framework has developed implementations that encourage and contribute to social, economic, and environmental sustainability within the rural villages of China. Their work contradicts the typical interests of urban design by refocusing on the fundamental community system that is the village. Rural Urban Framework identifies five types of villages in modern society: the urban village, the factory village, the suburban village, the contested village, and the rural village. Each typology recognizes the initial formation of the village and recognizes the inevitable change that is to come of these villages as urbanization of metropolitan areas encroaches or manipulates the lifestyles of each village. With the belief that the future of global communities involves the prosperity of the rural landscape, Rural Urban Framework offers their service as "a working methodology that sets up a productive dialogue between research and design in order to make architecture that actively contributes to the future transformation of the areas in which it is located."13

Of the five types, the Contested Village and Rural Village reflect similarities in Rural America. In China, these Contested Villages are the communities which are in a transition run by legal and/or economic powers. The implementation of these forces has been met with much resistance and misunderstanding leaving these villages as plots of contention. The Rural Village appears to be untouched by the economic shifts of the past thirty years in the country; however, these rural villages now run on the economy of the city with the villages able workers sending income to the elders and children in the village.

\footnotetext{
${ }^{11}$ Ibid.

12 Ibid.

${ }^{13}$ Bolchover, Joshua, and Lin, John. Rural Urban Framework : Transforming the Chinese Countryside. Basel/Berlin/Boston: Walter de Gruyter GmbH, 2013. Accessed April 9, 2019. ProQuest Ebook Central.
} 
In the Tongiiang Village, in partnership with World Vision, Rural Urban Framework researched and designed a recycled brick school which now is seen as a prototype for sustainable urban development because of it's reuse of materials, innovation with limited resources, and potential for community spatial agency. ${ }^{14}$ In Mulan Village, Rural Urban Framework was faced with the situation of a (literally) shifting landscape due to the construction of a light rail in a Rural Village which was commissioned to add extra classrooms to it's Primary School. Their solution was one which creates a series of open spaces that could be used for the school and community and where the structure is designed to reinforce the disturbed earth which has affected the village by means of landslides and flash flooding. The addition in Mulan Village connects the pressing ecological issues with ecological education by creating a series of open spaces which will be used in different times of the day and extend the life of the space to be of use throughout the day. ${ }^{15}$

There is a theme of maximization and efficiency in the urban design world that translates to Rural America quite nicely. Not only maximizing what we've discovered design can do in the city, but applying this mindset to the complex systems that physically and socially bind Rural America.

\section{Four Focuses of Attention}

Through understanding the social systems of Rural America and analyzing relevant case studies, the following pages describe a proposal of Four Focuses of Attention to Sustain Rural Place for stakeholders to prioritize when designing for their towns. They have been developed to make the findings of urban design relevant and tangible to Rural America's community designers, leaders, and other stakeholders. Each Focus of Attention is associated with a question that pertains to a physical tangibility of space and a social implication that is related. Each focus and question should be considered when a rural place is looking towards new development, revitalisation, preservation, or renovation. Think of this as a guide to creating an intentional mindset for designing Rural America. By considering these focuses, a community can be preserved, establish autonomy to protect their social economy, and be empowered to integrate livability principles.

\subsection{Representation}

Key Words: pride, character, unique, relationship

\footnotetext{
${ }^{14}$ Bolchover, Joshua, and Lin, John. Rural Urban Framework : Transforming the Chinese Countryside. Basel/Berlin/Boston: Walter de Gruyter GmbH, 2013. Accessed April 9, 2019. ProQuest Ebook Central.

${ }^{15}$ Ibid.
} 
The first focus of attention to sustain rural place is representation and making an intentional effort to create pride in a community. A space that reflects the community is not just artsy or innovative, it allows for the community to have pride over their space. This need for territorialism is reflective of the differing social systems of Rural America in relation to how security is executed as opposed to Metropolitan America. The question of this focus is:

\section{What about the space is represents this community?}

Community leaders and decision makers should ask themselves this question when evaluating if a space in their community is a successful and efficient place. The question asks people to identify specific physical characteristics of a space and relate it to themselves and their community. By having a representational space, community leaders can advertise it as a source of pride in their community. This also encourages the community to get involved.

\subsection{Agency}

Key Words: delegate, ownership

The second focus of attention to sustain rural place is to enable community spatial agency. Communities need to allow citizens to become actively involved in their community and give them a sense of ownership. The question of this focus is:

\section{How is the community responsible for this space?}

By asking this question, a space can delegate its responsibility to the community. Too create community agency means to allow citizens a sense of ownership to the space. Community leaders should give citizens input as to how the space should be used now and what it might look like in the future.

\subsection{Access}

Key Words: around-the-clock access, security, specificity

The third focus of attention to sustain rural place is to create a space that is usable throughout the year and at all times of the day. There is no need in a rural community with a small population to spread out activities to multiple areas of town. This does not mean to create multi use spaces that lack specificity; rather, multiple programs should be specified to the space in question. The question of this focus is:

What will happen here in the morning, afternoon, evening, and night? 
This question requires specificity to be carefully considered! Designing a space in a rural community is especially meaningful as it is sure to be a noticeable change in a community and will not be drowned out by its surrounding context. Defining the program of spaces in the planning process also ensures a level of security as it means that the area will be intentionally occupied regularly and therefore maintained and kept up. This is the power of giving people a sense of ownership of space!

\subsection{Centralization}

Key Words: interconnected systems, connectivity, proximity

The fourth focus of attention to sustain rural place is to centralize systems. Systems can include pedestrian traffic, agriculture, retail spaces, and roads just to name a few. By centralizing systems, rural environments can benefit from the effects of density that are seen in urban environments; primarily efficiency. The question of this focus is:

\section{Are all of the systems happening in this space concentrated?}

\section{How is this space connected to other community systems?}

This focus draws upon the works of what density does in Metropolitan America. Not only is centralizing and concentrating physical elements like electricity, water, sewage lines efficient and economical, but centralizing automobile and pedestrian traffic makes for a more efficient, economical, and sustainable environment!

\section{Conclusion: Making Urban Design Prevalent + Creating A Tangible Tool}

The above analysis and proposed Four Focuses of Attention have culminated into the development of a booklet for rural community leaders, A Guide to Sustaining Rural Place (Appendix C). By creating a tangible tool for Rural America, community leaders can begin to take advantage of the progress made by the urban design industry and apply these findings to their homes. Implementation strategies are included in the booklet and act as a basic guide to preserving the heart of Rural America, it's people and the tight knit communities which are essential to their survival and livability. 


\section{Bibliography}

The American Institute of Architects. 2005. "Livability 101: What Makes A Community Livable?". Washington D.C.: The American Institute of Architects. https://www.aia-mn.org/wp-content/uploads/Livability101.pdf.

Bolchover, Joshua, and Lin, John. Rural Urban Framework : Transforming the Chinese Countryside. Basel/Berlin/Boston: Walter de Gruyter GmbH, 2013. Accessed April 9, 2019. ProQuest Ebook Central.

Design: SD. 2007. "10 Design Principles For Livable Rural Communities". Brown County, South Dakota: Dakotafire Media. http://www.designsd.org/design-principles.html.

Florida, Richard. 2018. "The 3 Rural Americas". Citylab. https://www.citylab.com/equity/2018/06/the-three-rural-americas/561791/.

Lipschitz, Forbes. "Not in My City: Rural America Urban Dumping Ground." Architecture_MPS 6, no. 2 (2014): 1-21.

"Methodology - SEED Network". 2019. SEED Network. Accessed May 25. https://seednetwork.org/tools/methodology/.

"Shifting Geography Of Population Change". 2018. USDA ERS. https://www.ers.usda.gov/topics/rural-economy-population/population-migration/shifting -geography-of-population-change/.

Stauskis, Gintaras, and Frank Eckardt. "Empowering Public Spaces as Catalysers of Social Interactions in Urban Communities." Town Planning and Architecture 35, no. 2 (2011): 117-28.

Thayer, Robert L. LifePlace: Bioregional Thought and Practice. Univ of California Press, 2003.

University of Arkansas Community Design Center. 2010. "Townscaping An Automobile-Oriented Fabric: Farmington, Arkansas". Fayetteville, Arkansas: UACDC. https://s3.amazonaws.com/uacdc/Farmington_Townscaping-an-Automobile-Oriented-Fa bric.pdf. 
Appendices

\section{A: The AIA's 10 Principles for Livable Communities}

1. Design on a Human Scale: Compact, pedestrian-friendly communities allow residents to walk to shops, services, cultural resources, and jobs and can reduce traffic congestion and benefit people's health

2. Provide Choices: People want variety in housing, shopping, recreation, transportation, and employment. Variety creates lively neighborhoods and accommodates residents in different stages of their lives.

3. Encourage Mixed-Use Development: Integrating different land uses and varied building types creates vibrant, pedestrian-friendly and diverse communities.

4. Preserve Urban Centers: Restoring, revitalizing, and infilling urban centers takes advantage of existing streets, services, and buildings and avoids the need for new infrastructure. This helps to curb sprawl and promote stability for city neighborhoods.

5. Vary Transportation Options: Giving people the option of walking, biking and using public transit, in addition to driving, reduces traffic congestion, protects the environment and encourages physical activity.

6. Build Vibrant Public Spaces: Citizens need welcoming, well-defined public places to stimulate face-to-face interaction, collectively celebrate and mourn, encourage civic participation, admire public art, and gather for public events.

7. Create a Neighborhood Identity: A "sense of place" gives neighborhoods a unique character, enhances the walking environment, and creates pride in the community.

8. Protect Environmental Resources: A well-designed balance of nature and development preserves natural systems, protects waterways from pollution, reduces air pollution, and protects property values.

9. Conserve Landscapes: Open space, farms, and wildlife habitat are essential for environmental, recreational, and cultural reasons.

10. Design Matters: Design excellence is the foundation of successful and healthy communities. 
B: 10 Design Principles for Livable Rural Communities: A project of Design: SD - Analysis

Words which are in bold italics have been added from AIA's original principles. Below each principle is the AIA's original livability statement with words that have been excluded from the adaptation striked out.

1. Design on a Human Scale: Communities that provide safe options for walking, biking and using public transit - in addition to driving - to places such as shops, services, cultural resources and jobs can encourage community interaction and benefit people's health.

Design on a Human Scale: Gompat, pedestrian-friently eommtnities allow residents to to shops, services, cultural resources, and jobs and can benefit people's health

2. Provide Choices: People want variety in housing, shopping, recreation, transportation and employment. Variety creates lively communities and accommodates residents in different stages of their lives.

Provide Choices: People want variety in housing, shopping, recreation, transportation, and employment. Variety creates lively neighborts and accommodates residents in different stages of their lives.

3. Plan for mixed uses: Integrated land uses that work well together, such as retail, residential and green space, and separating land uses that don't such as manufacturing and downtown retail, creates vibrant, pedestrian-friendly and diverse communities. Eneure Mixed-Use Developmente Integrating different land uses and varied building types creates vibrant, pedestrian-friendly and diverse communities.

4. Preserve the Community's Core: Restoring, revitalizing and infilling Main Streets and downtowns takes advantage of existing streets, services and buildings, avoiding the need for new infrastructure. Strong downtowns help preserve and enhance a community's identity.

Preserve Urban Centers: Restoring, revitalizing, and infilling urban centers takes advantage of existing streets, services, and buildings and avoids the need for new infrastructure. This

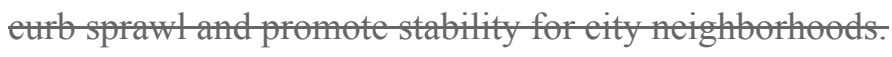

5. Build Connections: Prominent gateways into communities, clear wayfinding and connections between neighborhoods that accommodate both walking and driving can serve as guides to help visitors and residents know where they are and how to get where they are going. 
Vary Transportation Options: Giving people the option of walking, biking and using publie transit, in addition to driving, reduees traffie eongestion, proteets the environment and eneourages physieal aetivity.

6. Create Shared Social and Public Spaces: Citizens need welcoming, well-defined public places to stimulate face-to-face interaction, collectively celebrate and mourn, encourage civic participation, admire public art and gather for public events.

Build Vibrant Public Spaces: Citizens need welcoming, well-defined public places to stimulate face-to-face interaction, collectively celebrate and mourn, encourage civic participation, admire public art, and gather for public events.

7. Promote Community Identity: A "sense of place" gives communities a unique character, enhances appeal for visitors and creates pride in the community.

Ereate a Neighborhood Identity: A "sense of place" gives neighborhoods a unique character, enhances the walking environment, and creates pride in the community.

8. Conserve Natural Resources and Landscapes: Designing development with the surrounding natural world also in mind reduces air and water pollution, protects property values, preserves agricultural and natural systems and encourages people's connection to those systems. Vibrant landscapes can provide diverse recreational opportunities for residents and visitors.

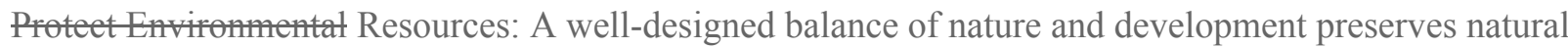
systems, protects waterways from pollution, reduces air pollution, and protects property values.

9. Develop Strategies for Economic Development and Marketing: Plans for building the community's economic health and spreading the word about its assets should be part of a community's design discussions. Beautiful, functional spaces can enhance a community's other efforts.

Conserve Landseapes: Open spaee, farms, and wildlife habitat are essential for environmental, reereational, and eultural reasons.

10. Design Matters: Design excellence is the foundation of successful, healthy and vibrant communities.

Design Matters: Design excellence is the foundation of successful and healthy communities. 
C: A Guide to Sustaining Rural Place: A tool for rural leaders to implement place making principles in Rural America

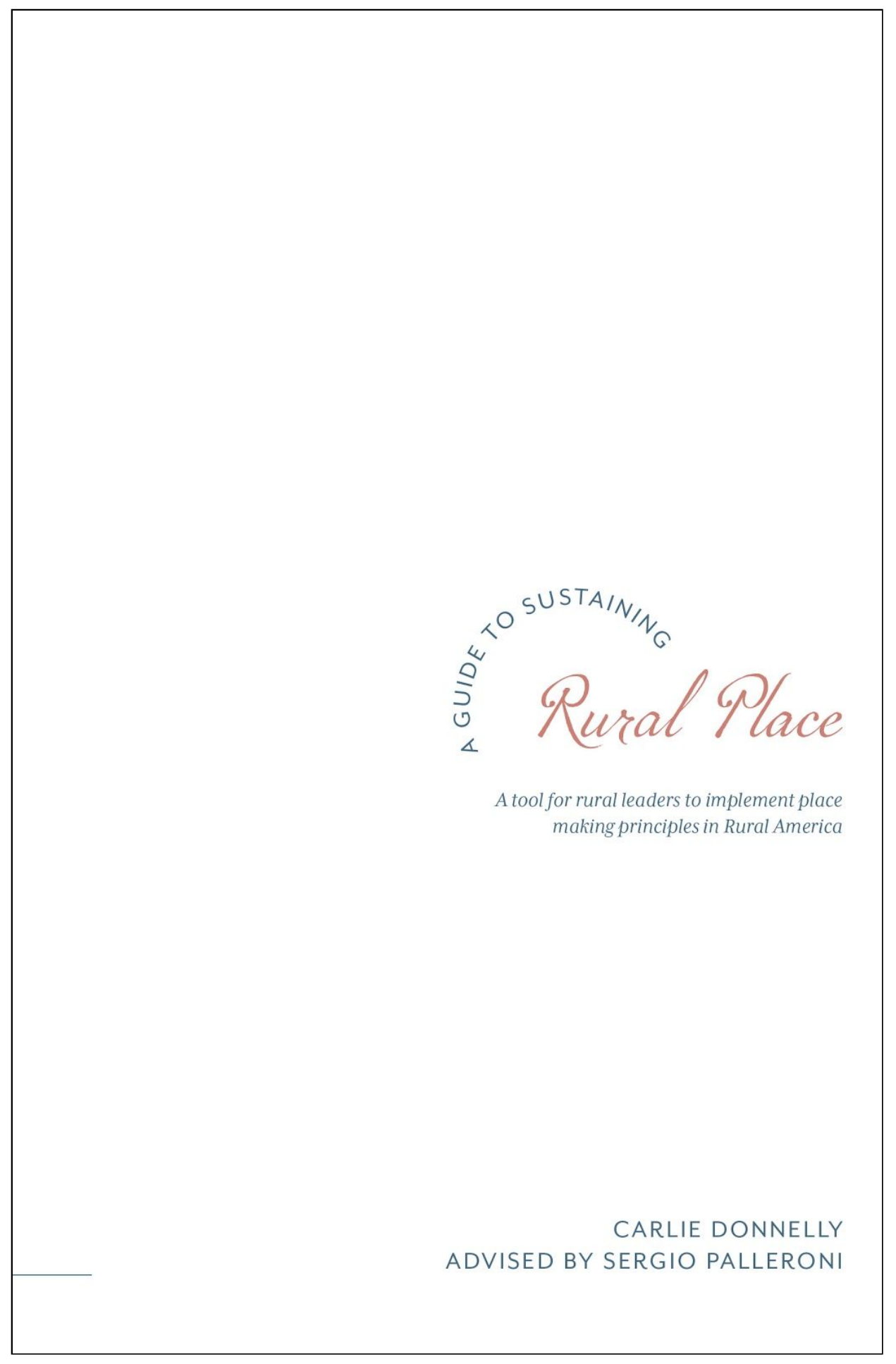




\section{table of contents}

$4 \quad$ place making

$5 \quad$ livable communities

8 four focuses of attention

representation

agency

access

centralization

14 key take aways 


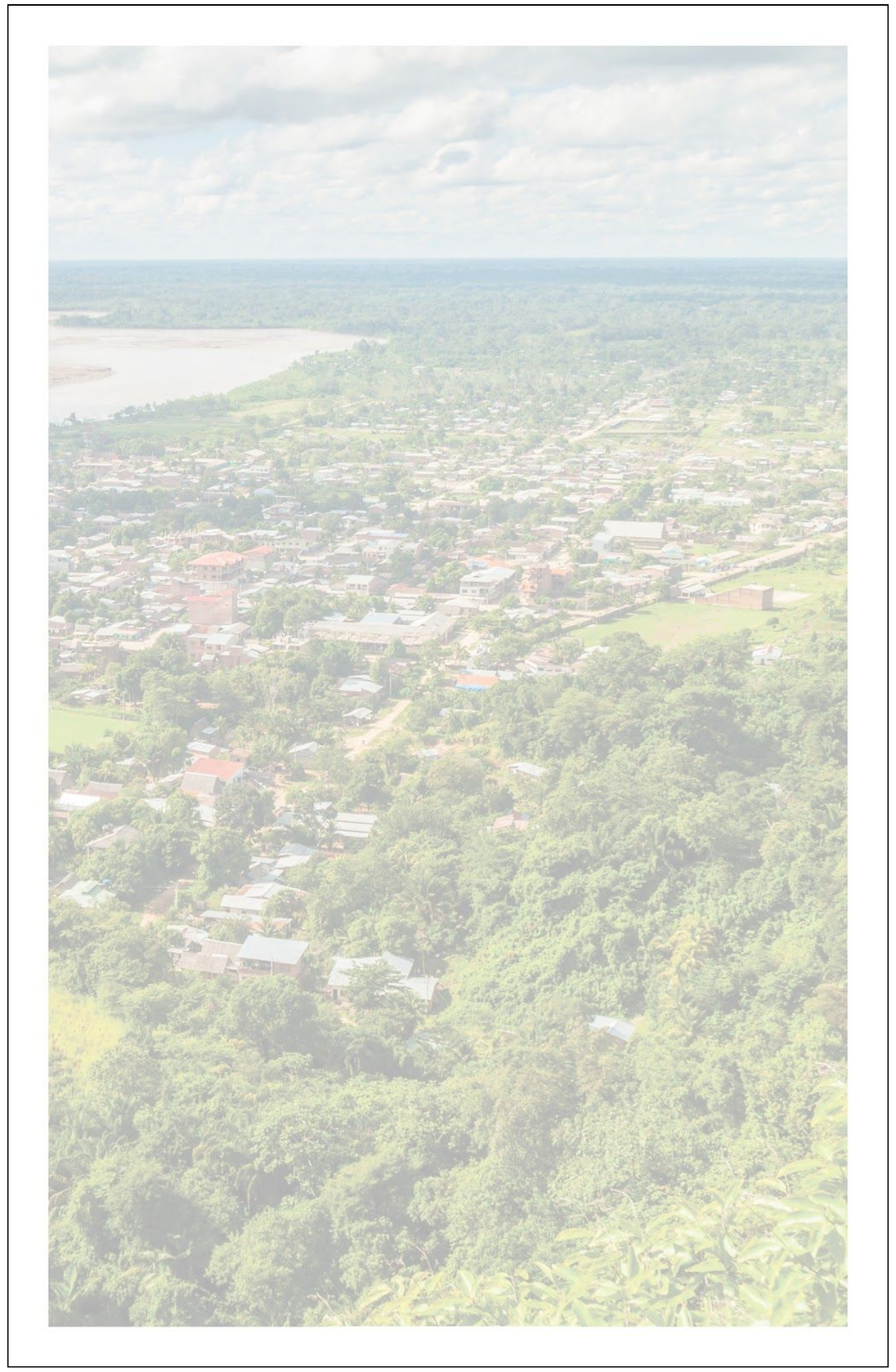




\section{place making}

\section{about this guide}

This guide has been created as a tool for the rural community, rural community leaders, and designers as a bridge between contemporary urban design principles and their application to Rural America.

\section{why do we need this?}

Urban environments have benefited by the discoveries made by urban designers, architects, and urban planners over the past century and even more greatly over the past few decades. This knowledge and the principles that have been derived and accepted from this knowledge positively impact the sustainability of social centers. Rural America can benefit from the knowledge collected in this industry and should learn from such principles to create spaces that benefit their own communities.

\section{where these thoughts started}

Several organizations have made great progress in identifying place making principles that are applicable specifically to rural environments. These principles aim to be sustainable in multiple areas. We have looked at two organization's existing metrics to guide our own approach: The SEED Network and design: South Dakota. 


\section{livable communities}

\section{SEED Principles}

1. Advocate with those who have a limited voice in public life 2 . Build structures for inclusion that engage stakeholders and allow communities to make decisions

3. Promote social equality through discourse that reflects a range of values and social identities

4. Generate ideas that grow from place and build local capacity

5. Design to help conserve resources and minimize waste

For more information, visit

https://seednetwork.org/tools/methodology/

design: South Dakota's

10 Principles for Livable Rural Communities

1. Design on a Human Scale

2. Provide Choices

3. Plan for mixed uses

4. Preserve the Community's

Core

5. Build Connections

6. Create Shared Social and

Public Spaces

7. Promote Community Identity
8. Conserve Natural Resources and Landscapes

9. Develop Strategies for Economic Development and Marketing

10. Design Matters

For more information, visit http://www.designsd.org/ design-principles.html 


\section{Let's make this applicable to you!}


Apply the following ideas when approaching reform, change, or new development to your community spaces. This will ensure community dedication for years to come.

The next pages will walk you through the vital Four Focuses of Attention. They are comprised of a question followed by examples of actionable steps to take. 


\section{FOUR FOCUSES}

OF ATTENTION

to sustain rural place 


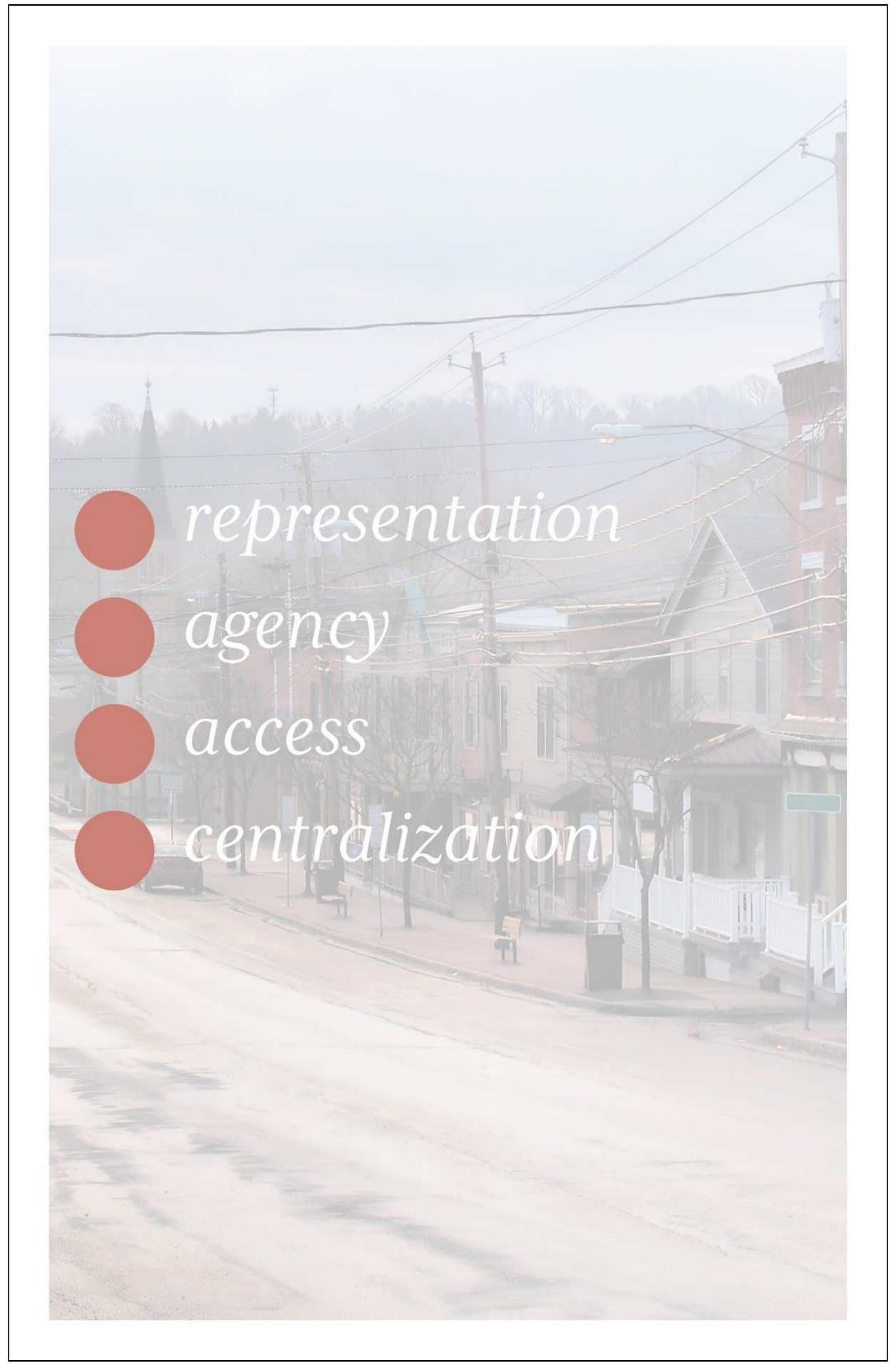




\section{representation}

pride, character, unique, relationship

\section{A space that reflects the community}

is not just artsy or innovative, it allows for the community to have pride over the space.

1 Ask the following question:

What about this space represents the community?

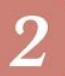

If this can be answered: If this can't be answered:

Advertise it! This can be a source of pride for the Get the community involved in creating a community!

space that they are proud of.

3 methods for representing a community

Display trophies of local teams and organizations from their accomplishments.

Invite multiple groups into the space to help repaint the walls.

Display artwork creates in the classrooms of the local school.
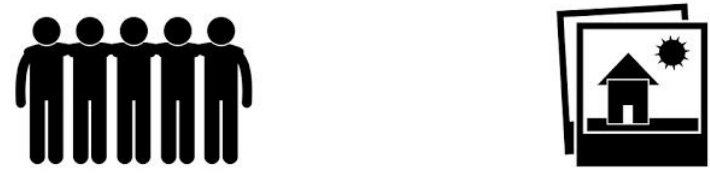


\section{agency \\ delegate, ownership}

To create community agency means...

to allow citizens a sense of ownership to the space. View this as delegating the space to citizens in specific ways. Give them input as to how the space should be used now and what it might look like in the future.

\section{Ask the following question:}

How is the community responsible for this space?

If this can be answered: If this can't be answered:

2 Ensure that they have pride over the space. Include them in future decisions about the space.

Make this space the topic of the next community meeting and ask the community how they would potentially use the area.

Advertise the space as a place for community groups too meet.

Make this space a regular conversation piece in community meetings and allow community members to implement their own suggestions.
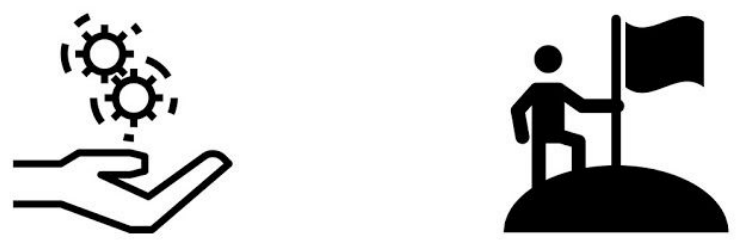

11 


\section{access}

around-the-clock access, security, specificity

When a space is intentionally occupied...

you achieve a level of security and purpose.

By establishing specific activities to regularly occur in a public or semipublic space, you ensure that the space will be maximized.

1 Ask the following question:

What happens here in the morning, afternoon, evening, and night?

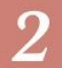

\section{If this can be answered:}

If this can't be answered:

Are all of these times of day met most of the time? Great!

Create a list of groups in the community who could benefit from this space

Are there gaps? Look at the and reach out to them. next column.

Look at how Rural Urban Framework created an educational space that is used throughout the day:

http://www.rufwork.org/index.php?/project/mulanvillage/

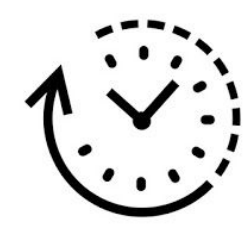




\section{centralization}

interconnected systems, connectivity, proximity

Systems can include...

pedestrian traffic, agriculture, retail spaces, roads, etc.

By centralizing systems, rural environments can benefit from the effects of density that are seen in urban environments; primarily efficiency.

1 Ask the following questions:

Are all of the systems happening in this space concentrated?

How is this space connected to other community systems?

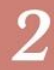

If these can be answered:

Examine why they are more efficient by being physically closer together. Encourage this proximity throughout the space.

If these can't be answered:

Identify systems that could be more efficient if they were moved. Think of pathways that could be created to make these spaces more efficient.

Look at how the University of Arkansas Community Design Center centralized the systems of the small town of Farmington Arkansas:

http://uacdc.uark.edu/work/townscaping-an-automobileoriented-fabric 


\section{key take aways}

\section{place making is useful}

Knowledge on creating places that encourage social interaction and sustain a community exists! We simply need to apply it to a rural setting to take advantage of what urban environments have discovered for us!

\section{look at the 4 focuses of attention + answer these questions about your community spaces}

What about this space represents the community? How is the community responsible for this space? What will happen here in the morning, afternoon, evening, and night? Are all of the systems happening in this space concentrated? How is this space connected to other community systems?

\section{adjust + reach out}

The SEED Network and design: South Dakota are excellent resources to discover how to implement intentional design choices into your community. The Four Focuses of Attention also considered the works of Rural Urban Framework and the University of Arkansas Community Design Center when developing these approaches to implementation.

https://seednetwork.org/

http://www.designsd.org/

http://www.rufwork.org/

http://uacdc.uark.edu/ 